\title{
Probabilistic, high-resolution tsunami predictions in North Cascadia by exploiting sequential design for efficient emulation
}

\author{
Dimitra M. Salmanidou ${ }^{1}$, Joakim Beck ${ }^{2}$, and Serge Guillas ${ }^{1}$ \\ ${ }^{1}$ 1Department of Statistical Science, University College London, Gower Street London WC1E 6BT, United Kingdom \\ ${ }^{2}$ Computer, Electrical and Mathematical Sciences and Engineering, King Abdullah University of Science \& Technology \\ (KAUST), Thuwal, Saudi Arabia \\ Correspondence: Dimitra M. Salmanidou (d.salmanidou.12@ucl.ac.uk)
}

\begin{abstract}
The potential of a full-margin rupture along the Cascadia subduction zone poses a significant threat over a populous region of North America. Traditional probabilistic tsunami hazard assessments produce hazard maps based on simulated prediction of tsunami waves either under limited ranges of scenarios or at low resolution, due to cost. We use the GPU-accelerated tsunami simulator VOLNA-OP2 with a detailed representation of topographic and bathymetric features. We replace the simu-

5 lator by a Gaussian Process emulator at each output location to overcome the large computational burden. The emulators are statistical approximations of the simulator behaviour. We train the emulators on a set of input-output pairs and use them to generate approximate output values over a six-dimensional scenario parameter space, e.g., uplift/subsidence ratio, maximum uplift, that represent the seabed deformation. We implement an advanced sequential design algorithm for the optimal selection of only sixty simulations. This approach allows for a first emulation-accelerated computation of probabilistic tsunami hazard in the region of the city of Victoria, British Columbia. The low cost of emulation provides for additional flexibility in the shape of the deformation, which we illustrate here, considering two families, buried rupture and splay-faulting, of 2,000 potential scenarios.
\end{abstract}

\section{Introduction}

The Cascadia subduction zone is a long subduction zone that expands for more than 1,000 km along the Pacific coast of North America; from Vancouver Island in the North to North California in the South (Fig. 1). The zone lies on the interface of the subducting oceanic plate of Juan de Fuca and the overriding lithospheric plate of North America. Earthquake-induced tsunamis generated from the Cascadia subduction zone pose an imminent threat for the west coasts of the United States and Canada but also other coastal regions in the Pacific Ocean. Historical and geological records show that great plate boundary earthquakes were responsible for large tsunami events in the past (Clague et al., 2000; Goldfinger et al., 2012). A sequence of great earthquakes has been inferred for the region over the last $\sim 6,500$ years with an average interval rate of $500-600$ years (individual intervals may vary from a few hundred to 1,000 years) (Atwater and Hemphill-Haley, 1997; Clague et al., 2000; Goldfinger et al., 2003, 2012). The most recent megathrust earthquake in the Cascadia subduction zone was the 1700 earthquake, the timing of which was inferred from records of an orphan tsunami in Japan (Satake et al., 1996; Satake, 2003). The moment magnitude $(\mathrm{Mw})$ of the earthquake was estimated close to 9 , with a rupture length of ca. $1100 \mathrm{~km}$, likely rupturing 
the entire zone (Satake, 2003).

There exists a large level of uncertainty with regard to the level of destruction that similar events could cause in the future. Major tsunamis in historical times have not caused significant damage to infrastructure in the west coast of British Columbia (Clague et al., 2003), partly attributed to the less densely and scarce populated areas in the region. However, the risk of such an episode nowadays has increased following an increase in urbanisation. The most recent major tsunami impacting the area was generated by the 1964 Great Alaskan earthquake on the 27th March 1964. Although no casualties were reported in Canada, the tsunami caused millions of damage in the west coast of Vancouver Island (Clague et al., 2000, 2003). Studies examining the impact of tsunami in Cascadia have mostly focused on a worst-case scenario potential (Cherniawsky et al., 2007; Witter et al., 2013; Fine et al., 2018); a few probabilistic studies exist, primarily assessing hazard potential on the U.S. coastline (Park et al., 2017) for a limited number of scenarios at high resolution, or at individual local points (Guillas et al., 2018) for a large number of scenarios but at a moderate resolution of $100 \mathrm{~m}$.

Probabilistic approaches allow for the exploration of large scenario distributions that benefit risk-informed decision making. The probabilistic approach is to treat the uncertain scenario parameters as random variables and then propagate the parameter uncertainty to model outputs. Uncertainty quantification aims to efficiently estimate the resulting variability in the simulation output, for instance in the simulated maximum tsunami wave heights on a set of locations. Thus, one needs to run the tsunami simulator for many scenarios with parameter values drawn from a chosen probability distribution, defining our prior belief about different scenarios' probability. Tsunami modelling studies, however, often require high accuracy, high resolution computations to assess the hazard and risk at a level that is meaningful for coastal communities. The parameter space dimension is also typically high, and the number of expensive numerical simulations needed to resolve the statistics about the output tends to be large and thus unaffordable. Statistical emulators (also known as a statistical surrogate models) can be called to address these issues (Behrens and Dias, 2015). We propose using a statistical surrogate approach, also called emulation, in which one approximates simulation outputs of interest as a function of the scenario parameter space. Such approaches have been implemented for uncertainty quantification of tsunami hazard at various settings (Sraj et al., 2014; Salmanidou et al., 2017, 2019; Guillas et al., 2018; Denamiel et al., 2019; Snelling et al., 2020; Gopinathan et al., 2021).

To build the emulators, training data are of paramount importance. In tsunami hazard, where observations of past events are limited, these training data originate from numerical experiments that have been mainly constrained by some physical understanding of the widest range of possible scenarios in order to cover any possible event through the emulation process, since interpolation, not extrapolation, is the core technique. The role of experimental design in the scientific studies becomes, thus, critical as it aims to select the optimal sets of variables that contribute to the variance in the response and, in parallel, minimise the numbers of the runs needed for a desired accuracy. Several methods exist in the literature, from which two commonly occurring designs are the fixed/one-shot and the adaptive/sequential design. In fixed designs, such as the Latin Hypercube sampling, the sample size of the experiments is prescribed. These designs have good space-filling properties, but may waste computational resources over unnecessary regions of the input space. On the other hand, sequential designs adaptively select the next set of experiments to optimise the training data for fitting the emulators. Such a design can be determined by the very 


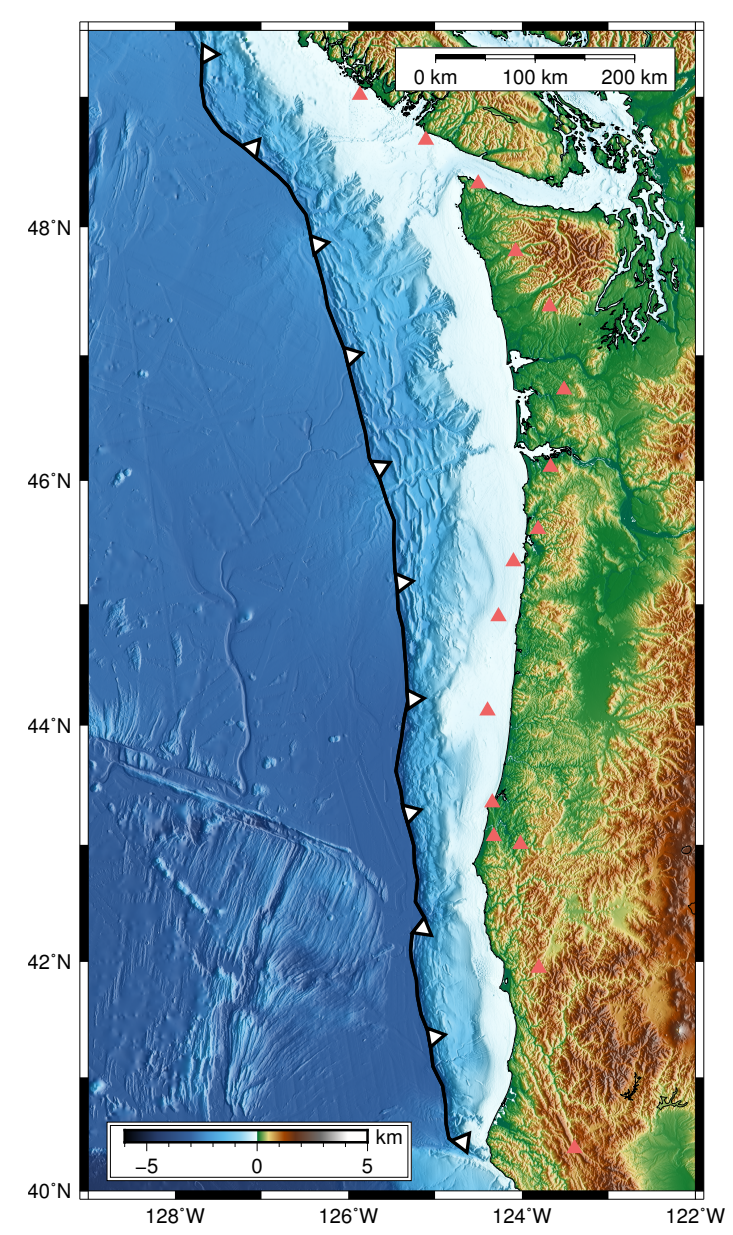

Figure 1. The domain of interest. The black line and white arrows depict the location of the trench, the orange triangles show the points used to drive the maximum subsidence. The reference point of the scale bar is assumed to be the bottom left corner of the map.

efficient Mutual Information for Computer Experiments (MICE) algorithm (Beck and Guillas, 2016) that we utilise in this study for probabilistic tsunami hazard prediction in North Cascadia.

Our study builds a methodology that employs existent methods and tools for the design of computer experiments and statistical emulation in order to quantify the uncertainty of tsunami hazard in British Columbia. The objective is to build Multi-Output Gaussian Process (MOGP) emulators and use them for probabilistic, high-resolution tsunami hazard prediction. The benefit of this approach is the use of a sequential design algorithm in the training to maximize the computational information gain over the multidimensional input space and adaptively select the succeeding set of experiments. The vertical seabed displacement over the Cascadia subduction zone was defined by its duration and a set of shape parameters. We develop a site-specific idealised model for the time-dependent crustal deformation along the subduction zone, controlled by a set of shape parameters. In our study, the shape parameters are the model input, and the values define a specific scenario. The tsunami hazard was 
modelled using the GPU-accelerated nonlinear shallow water equation solver VOLNA-OP2 (Reguly et al., 2018). The acceleration with GPUs makes it computationally feasible to run tsunami simulations on highly refined meshes for many scenarios. By a scenario, here, we mean a specific seabed deformation causing a tsunami outcome. For each location in a refined area of 5,148 mesh locations at the shoreline of Southeast Vancouver Island, we create a corresponding emulator of the expensive high-resolution tsunami simulator. The implementation of MOGP emulators finally allows us to predict the maximum tsunami heights at a high resolution, which can then be utilized to assess the probabilistic tsunami hazard for the region. The advantage is that only a relatively small number of expensive tsunami simulator runs, that constitute the training data for the emulators, needs to be performed. A fast evaluation of these emulators for untried input data is then performed to produce approximates of what the tsunami simulator output would have been. The emulators' technique of choice is a Gaussian process regression, which is also widely known as Kriging. The study workflow followed in this study can be divided in three stages (Fig. 2): I) the experimental set-up, II) the experimental design and III) the emulation. Each stage is described in detail in the following sections.

\section{Set-up of experiments}

To proceed with the numerical experiments, some choices with regard to the input data need to be made a priori. Hence, the first stage of the study deals with the set-up of the numerical experiments. This stage can prove critical as changes in the set-up at a later stage of the study (e.g. emulation stage) might result in the re-initiation of the process. Several aspects need to be considered some of which are: the choice of models and functions to perform the analysis, the input parameters to describe the seabed deformation and their ranges, the data acquisition and processing, and the grid configuration required to best represent the issues in question (see also yellow panel in Figure 2).

\subsection{Input parameters}

Most of the megathrust earthquake scenarios examine the possibility of buried rupture or splay-faulting rupture in the northern part of the segment (Priest et al., 2010; Witter et al., 2013; Fine et al., 2018). Trench breaching rupture scenarios were also studied by Gao et al. (2018). Varying methods have been used to represent the seabed displacement leading to tsunami excitation in the Cascadia subduction zone (Satake, 2003; Wang et al., 2003). In this study, an idealised geometry in the form of a cosine interpolation is employed for a smooth representation of the vertical component of the co-seismic seabed deformation. The maximum and minimum points of the interpolation function correspond to the locations of maximum uplift and subsidence respectively (Fig. 1). The points along the trench (60 locations) were defined by the morphological change between the undeformed ocean floor of the subducting Juan de Fuca plate, and the irregular deformed slope of the overriding North American plate. A full-length rupture is computed for all the scenarios presented in the study. Seven input parameters were considered to describe the deformation: the total rupture duration, the horizontal distance from the trench to a) the point of the 


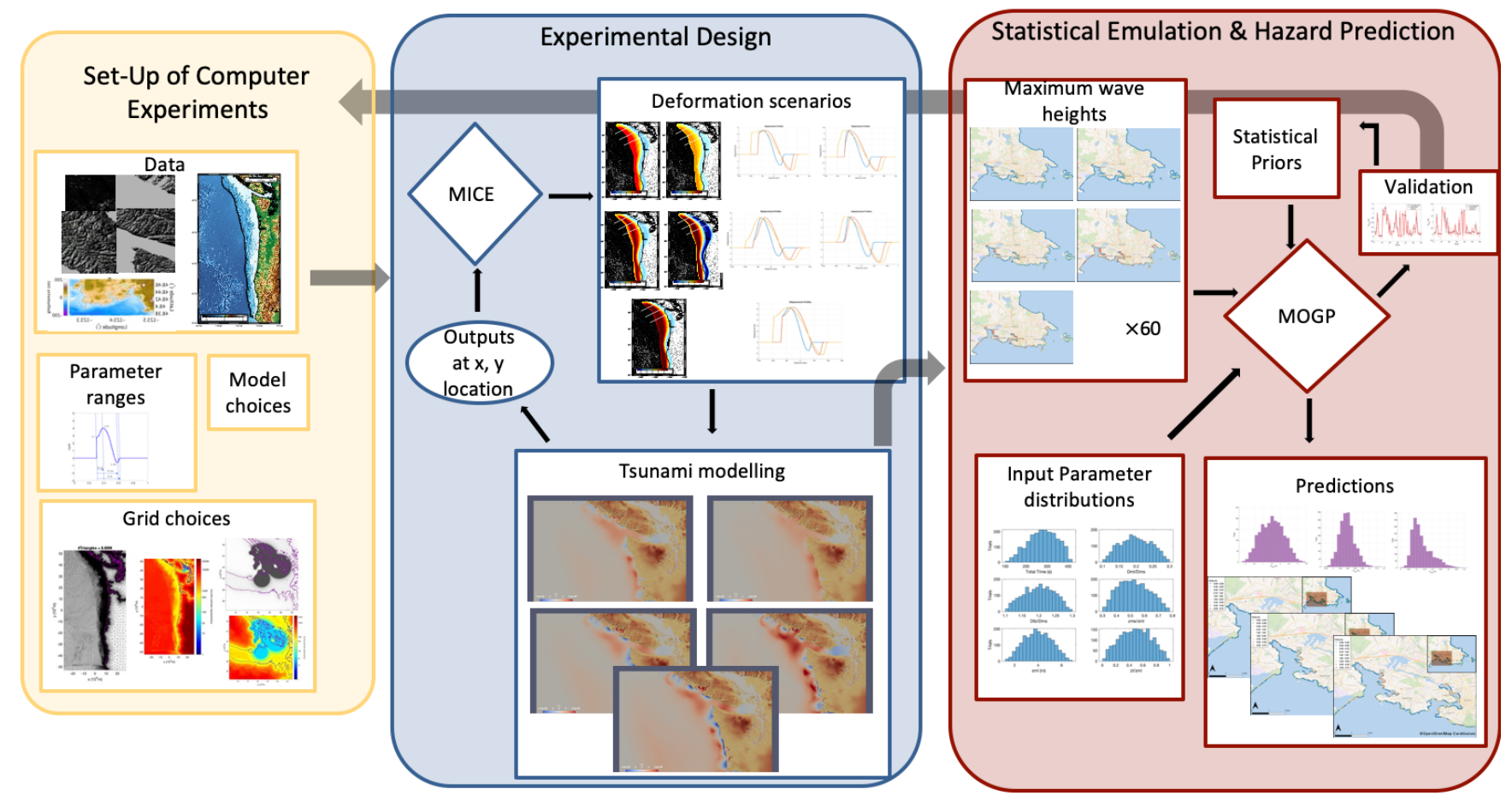

Figure 2. The graph of the workflow divides the study in three principal stages that are interlinked: stage 01 (yellow panel) comprises the study specification and set-up of the experiments, stage 02 (blue panel) comprises the study design and conduction of the numerical experiments and stage 03 (red panel) comprises the building of the emulators and their use for prediction. The maps in the predictions section of stage 03 are produced with the QGIS software using as base-maps the Wikimedia ${ }^{a}$ layers with data provided by OpenStreetMap contributors, 2021. Distributed under a Creative Commons BY-SA License ${ }^{b}$.

\footnotetext{
${ }^{a}$ maps.wikimedia.org

${ }^{b}$ https://www.openstreetmap.org/copyright
} 


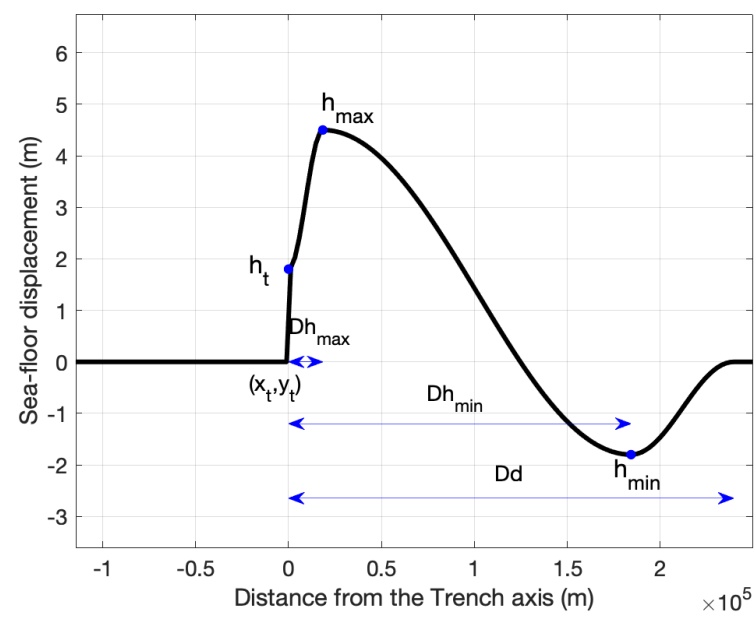

Figure 3. The geometry of the vertical seabed displacement. The parameters values to create the plot are: $D h_{\max } / D h_{\min }=0.1$, $D d / D h_{\min }=1.3, h_{\min } / h_{\max }=0.4, h_{\max }=4.5 \mathrm{~m}$ and $h_{t} / h_{\max }=0.4$

maximum uplift $\left.\left(D h_{\max }\right), \mathrm{b}\right)$ the point of maximum subsidence $\left(D h_{\min }\right)$ and c) the point where the deformation stops $(D d)$, the maximum uplift on the trench line $\left(h_{t}\right)$, the maximum uplift recorded $\left(h_{\max }\right)$ and the maximum subsidence $\left(h_{\min }\right)$ (Fig. 3). The duration, $t$, the maximum vertical displacement, $h_{\max }$, and the ratios of $h_{\min } / h_{\max }, h_{t} / h_{\max }, D h_{\max } / D h_{\min }$ and $D d / D h_{\min }$ are then utilised to model the deformation.

The choices for constraining some of these variables were motivated by the existing literature. For example, the duration of mega-thrust earthquakes may increase with increasing earthquake size. The co-seismic crustal deformation of earthquakes larger than Mw 8 can usually last for more than one minute (McCaffrey, 2011). The rupture duration recorded during the 2004 Sumatra-Andaman earthquake was approximately $500 \mathrm{~s}$, during which the $1,300 \mathrm{~km}$ zone ruptured at speeds of $2.8 \mathrm{~km} / \mathrm{s}$ (Ishii et al., 2005). The 2011 Tohoku earthquake, on the other hand, had a rupture duration that might have lasted approximately $150 \mathrm{~s}$ (Lay, 2018). These large variations in the rupture duration are not solely dependent on magnitude but on more complex rupture characteristics (Bilek and Lay, 2018; Lay, 2018). Assuming rupture speeds of 2.8-4 km/s, a rupture of 1,100 km in the Cascadia Subduction Zone would yield 275-393 s. A larger time range, $t$, varying between 100 and $420 \mathrm{~s}$ is considered for the simulations.

The seabed deformation of a future event in the Cascadia Subduction Zone cannot be predicted with certainty. The 1700 earthquake possibly caused a vertical displacement of ca. $4 \mathrm{~m}$ when considering a full length rupture (Satake, 2003). The subsidence of the event was inferred from microfossil data to have ranged between 0.5-1.5 $\mathrm{m}$ at several coastal sites in the Pacific Northwest (references in Satake et al., 2003). Similar or larger values have been observed in other great subduction zone earthquakes (Fujiwara et al., 2011; Maksymowicz et al., 2017). It is estimated, that splay-faulting rupture in the Northern part of the zone could result in an enhanced vertical displacement in the vicinity of the deformation front (Priest et al., 2010). Witter et al. (2013) modelled various deformation models for tsunami excitation with respect to a 1,000 km rupture length. They 
found that for events with recurrence rates of 425-525 years, splay-faulting may increase the maximum vertical displacement in the northern part of the zone (Olympic peninsula) to 7-8 $\mathrm{m}$ with maximum subsidence between 1.5-2.5 m. The maximum uplift and subsidence decrease to ca. $4 \mathrm{~m}$ and $1.4 \mathrm{~m}$ when moving southward (Cape Blanco) and splay-related displacement ceases below $42.8^{\circ}$ (Witter et al., 2013). Based on the above considerations the range of $h_{\max }$ was chosen to be 1-8 $\mathrm{m}$, with the ratio of $h_{\min } / h_{\max }$ estimated to range between 0.3-0.8. A full margin range was specified for the ratio of $h_{t} / h_{\max }$ : [0.0, 1.0]. Finally for the distance lengths the ratios of $D h_{\max } / D h_{\min }$ and $D d / D h_{\min }$ were varied between $[0.1,0.3]$ and $[1.1,1.3]$ respectively. Albeit the larger ranges to train the emulators, information on the source can be interpreted more efficiently in the prediction of the process (Section 4).

\subsection{Model choices}

For the tsunami simulations the numerical code VOLNA-OP2 was used (Reguly et al., 2018; Giles et al., 2020). The code has been employed at several occasions for the numerical simulation and the uncertainty quantification of tsunami hazard (Sarri et al., 2012; Salmanidou et al., 2017; Guillas et al., 2018; Gopinathan et al., 2021). By integrating the bathymetry displacement in VOLNA-OP2, the full tsunami process can be modelled from generation to onshore inundation. The code solves the depth-averaged Nonlinear Shallow Water Equations (NSWE) using a cell-centered finite volume scheme for the spatial discretisation. The 2nd order Runge-Kutta scheme in conjunction with a Strong Stability-Preserving (SSP) method is used for the temporal discretization. The utilisation of unstructured, triangular meshes allows for the incorporation of complex topographic and bathymetric features and accommodates the accurate representation of the region of interest. The VOLNA-OP2 has been massively parallelised and accelerated on general-purpose Graphics Processing Units (GPUs) and has been validated against known tsunami benchmarks and tested for its accuracy and computational efficiency (Giles et al., 2020).

For the tsunami hazard predictions the Multi-Output Gaussian Process (MOGP) emulators are utilised. To perform the analysis we use the MOGP emulation code which is maintained and freely distributed by the Research Engineering Group at the Alan Turing Institute. A Gaussian Process (GP) regression is the core component of the method. The GP fits a specified set of input and output variables using a multivariate Gaussian distribution with given mean and covariance functions, it also allows for the prior choice of the hyperparameters. The benefits of the MO approach is that this process can be run in parallel so that multiple emulators are fitted to the training input and output variables simultaneously while maintaining their independence in the solution. In this study we use as input variables the time and the shape parameters of the deformation (Section: 2.1) and as outputs the maximum tsunami heights observed at the coastline to build the emulators at 5,148 locations.

An active learning approach is employed to sequentially design the training data for the Gaussian process regression. A common approach is Active-Learning MacKay (ALM) where one chooses the design input in each sequential selection that produces the longest predictive variance. In this work, we use the active learning algorithm MICE that provides an informative design of training data for prediction at a lower computational cost than ALM (Beck and Guillas, 2016). The MICE algorithm extended the algorithm for near-optimal sensor placement by Krause et al. (2008) that uses a mutual information-based design criterion, to the setting of design of computer experiments with Gaussian process emulation. 


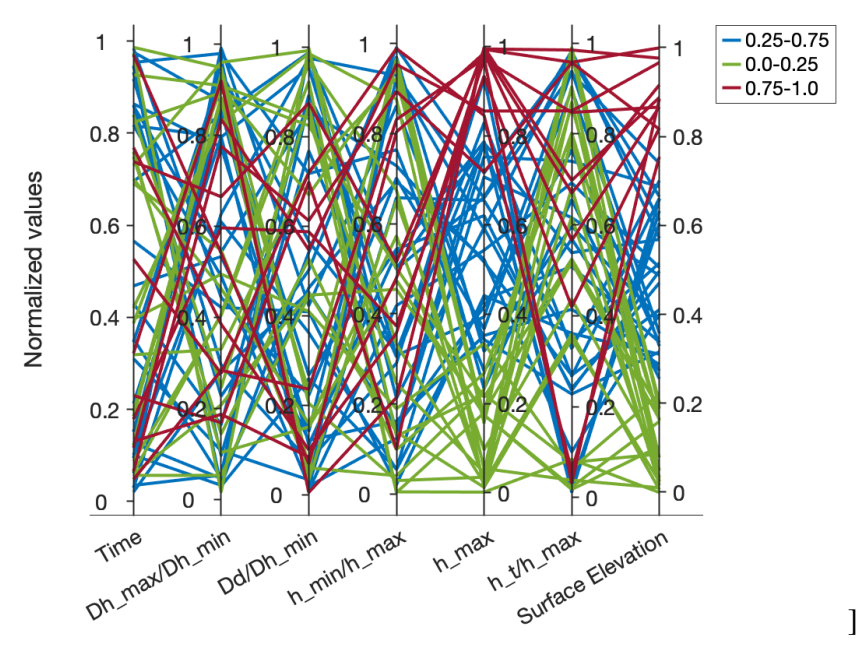

Figure 4. The Parallel Coordinates plot shows the choice of input parameters and the output maximum surface elevation at the design location for the 60 experiments. All the data values are normalized.

\subsection{Data and Grid configuration}

The digital bathymetry and topography data originate from a compilation of sources that vary in resolution from fine to coarse layers. For the coarse digital elevation layer the GEBCO_2019 Grid product, from the General Bathymetric Chart of the Oceans (GEBCO), is used which has a spatial resolution of 15 arc-seconds. For the high-resolution layer Digital elevation models from two data sets are merged: the Shuttle Radar Topography Mission (SRTM) and the National Oceanic and Atmospheric Administration (NOAA). The SRTM provide topographic data at a spatial resolution of 1 arc-second $(\sim 30 \mathrm{~m})$. The NOAA DEMs are distributed by the National Centers for Environmental Information (NCEI) and have a spatial resolution that can be as fine as $1 / 3$ arc-seconds $(\sim 9 \mathrm{~m})$, albeit without a full coverage. The data were interpolated and merged to generate a computational grid with a fine spatial resolution of $30 \mathrm{~m}$ in the region of interest that gradually decreases with increasing distance sustaining, however, a $500 \mathrm{~m}$ coastline resolution all across the computational domain. The interpolation and mesh generation algorithms were first implemented by Gopinathan et al. (2021) for the numerical simulations and the statistical emulation of tsunami hazard in the Makran subduction zone. The algorithms create a triangular grid by making use of the Gmsh mesh generator. Several design strategies were explored to perform the high-resolution analysis for the coastlines of Vancouver island in a way that satisfies the optimal trade-off between the different mesh set-ups and the affordable size of each run. The domain was, thus, split into 3 sub-domains that focused the high resolution outputs either at the coastlines of SW Vancouver island, or the West or the East part of the Juan de Fuca Strait. The results presented here show the tsunami propagation and inundation in the East part of the Strait; the computational mesh has 8,693,871 elements. 


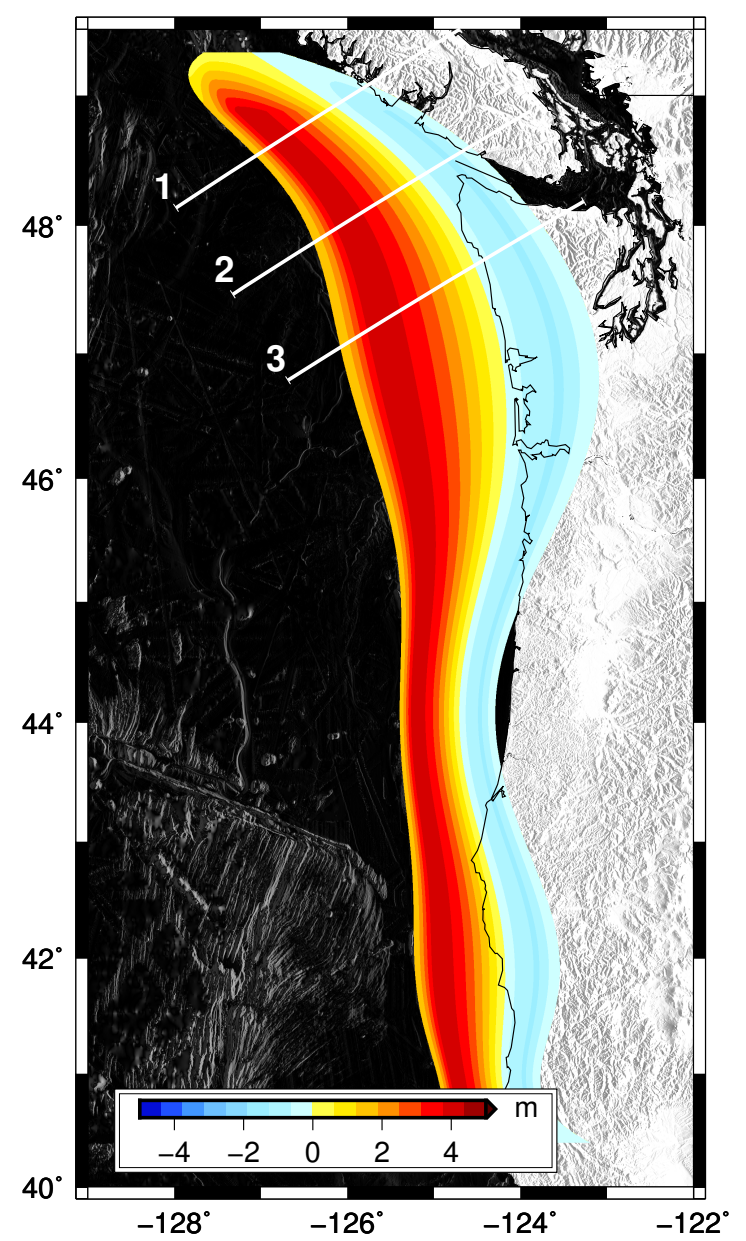

(a)

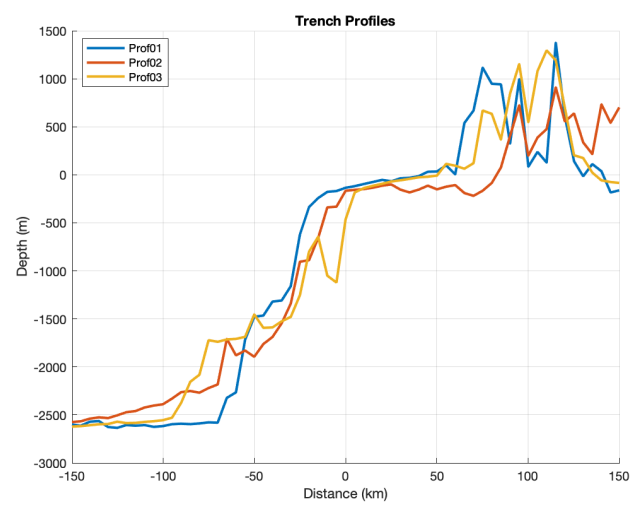

(b)

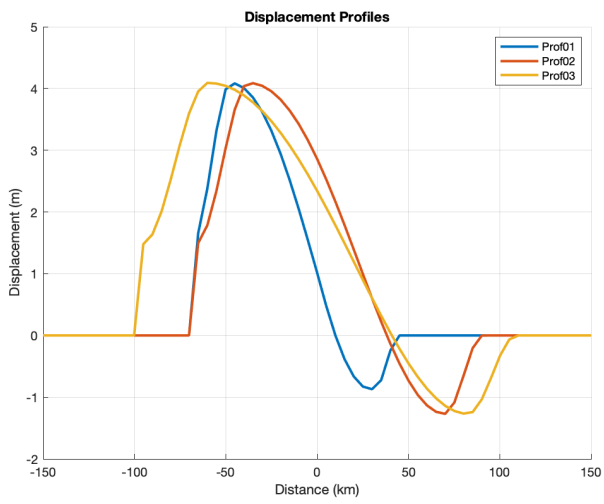

(c)

Figure 5. Top view of the seabed deformation for trial no. 24 and profiles of the trench and vertical displacement

\section{Experimental Design}

To automate the experimental process a workflow was developed exploiting high performance computing. In the core of the workflow (see also blue panel in Figure 2) lies the sequential design algorithm MICE which controls the scenario selection. The numerical experiments are divided in batches with each batch containing a set of five experiments. In the beginning of the process, MICE selects randomly the first set of experiments. Based on the selection of the initial input values (first five runs), the deformation for each scenario is computed. The input files required for the tsunami simulations are then produced, following the selected deformation. In the end of the tsunami simulations, the maximum elevation recorded at one location informative for the design (here we choose lon:-123.3934 and lat:48.4127, see Figure 8) is extracted and used as quantity of interest for MICE (Fig. 2). The algorithm then drives the selection of the subsequent sets in a way that allows for the optimal 
exploration of the input parameter space and the process is repeated. These iterations occur 12 times for a total of 60 scenarios. Each simulation runs for three hours in real time with a timestep of $d t=0.01 \mathrm{~s}$.

The tsunami generation follows the pattern of the bathymetry deformation across the 60 scenarios (Fig. 4). The parallel coordinates plot in Figure 4 represents the values of the input parameters selected by MICE and their associated output maximum sea surface elevation as recorded at the design location (black star in Fig. 7, 8). All the values are normalised, whereas the surface elevation values are categorised in three bins ([0-0.25],[0.25-0.75],[0.75-1]) for clarity. From the plot, some inference can be made on the influence of the input parameters on the output values. For example, the most influential parameter is the maximum uplift, as higher values result in higher surface elevation (Fig. 4). As an output from VOLNA-OP2 we extract the maximum tsunami heights as recorded on the cell-centres of the grid all across the domain's coastline. To build the statistical emulators the onshore maximum tsunami heights at the coast have been extracted from each simulation for the geographical region with longitude of: [-123.49, -123.22] and latitude: [48.38,48.55]. Within these boundaries, the cell-centres that correspond to the coastline that had recorded an elevation greater than $10^{-5} \mathrm{~m}$, for at least one scenario, were considered resulting in 5,148 locations (and subsequently emulators).

\subsection{A large scenario for initial validation}

Looking at a sample scenario demonstrates part of the process at an individual level. Scenario 24 is selected for its relevance to the maximum uplift in numerical studies of the event (Fig. 5) (Satake, 2003; Cherniawsky et al., 2007). The input parameter values of the scenario are: time $=281 \mathrm{~s}, D h_{\max } / D h_{\min }=0.18439, D d / D h_{\min }=1.18176, h_{\min } / h_{\max }=0.31049, h_{\max }=$ $4.09125 \mathrm{~m}$ and $h_{t} / h_{\max }=0.36047$. The tsunami generation and propagation is shown in the snapshots of Figure 6 . A tsunami trough is generated in the area of maximum subsidence and propagates east in the Strait of Juan de Fuca followed by the tsunami crest generated in the region of maximum uplift (Fig.6). The tsunami crest arrives in the Strait approximately 30 minutes after the tsunami generation and has reached the San Juan islands after 110 minutes of propagation (Fig.6). The tsunami trough arrives at the location of the offshore design gauge, near Victoria's breakwater (Fig.7), after ca. 50 minutes of propagation and records $-0.2 \mathrm{~m}$. The first wave crest in the gauge is recorded at ca. $100 \mathrm{~min}$ at an elevation of ca. $1.8 \mathrm{~m}$ (Fig.7). The arrival times come in close agreement with the arrival times computed by Fine et al. (2018) for two rupture scenarios with maximum uplifts of $4 \mathrm{~m}$ (burried rupture) and $8 \mathrm{~m}$ (splay-faulting rupture). The authors computed arrival times of 52 and $88 \mathrm{~min}$ for the first wave trough and wave crest respectively at a similar location (Victoria's breakwater), the corresponding minimum water levels were $-0.96 \mathrm{~m}$ and $1.63 \mathrm{~m}$ (Fine et al., 2018). The maximum wave elevation is in close agreement with the maximum wave amplitude of scenario 24. The discrepancies in the negative wave troughs can be attributed to the discrepancies in maximum subsidence between the two rupture scenarios (around $-2 \mathrm{~m}$ in the burried rupture model by Fine et al. (2018), whereas -1.27 $m$ in the scenario selected by MICE).

Similar values have been recorded in other numerical studies. Clague et al. (2000) estimated wave run-ups ranging between 1-5 $\mathrm{m}$ in the city of Victoria. Cherniawsky et al. (2007) computed a maximum wave elevation of ca. $2 \mathrm{~m}$ in Victoria's harbor, with larger values concentrated in small bays around the area. Larger water elevations have been computed by AECOM (2013) for a Mw 9 earthquake, having a maximum uplift of $6.2 \mathrm{~m}$ and maximum subsidence of $-2.3 \mathrm{~m}$. The earthquake-induced tsunami 
https://doi.org/10.5194/nhess-2021-63

Preprint. Discussion started: 9 March 2021

(c) Author(s) 2021. CC BY 4.0 License.
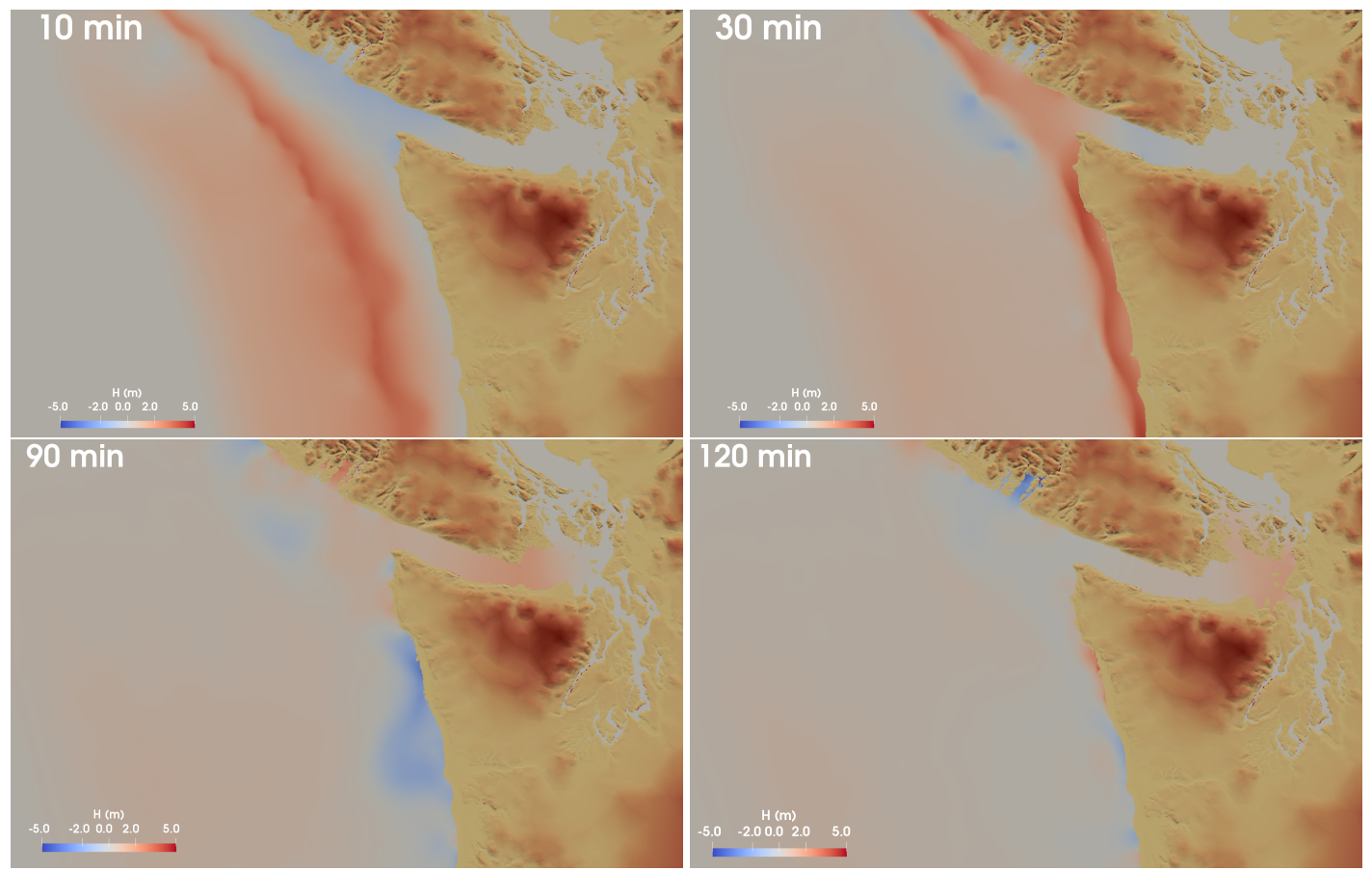

Figure 6. Snapshots of the tsunami propagation of scenario 24 at time intervals $T=10,30,90$ and 120 minutes.

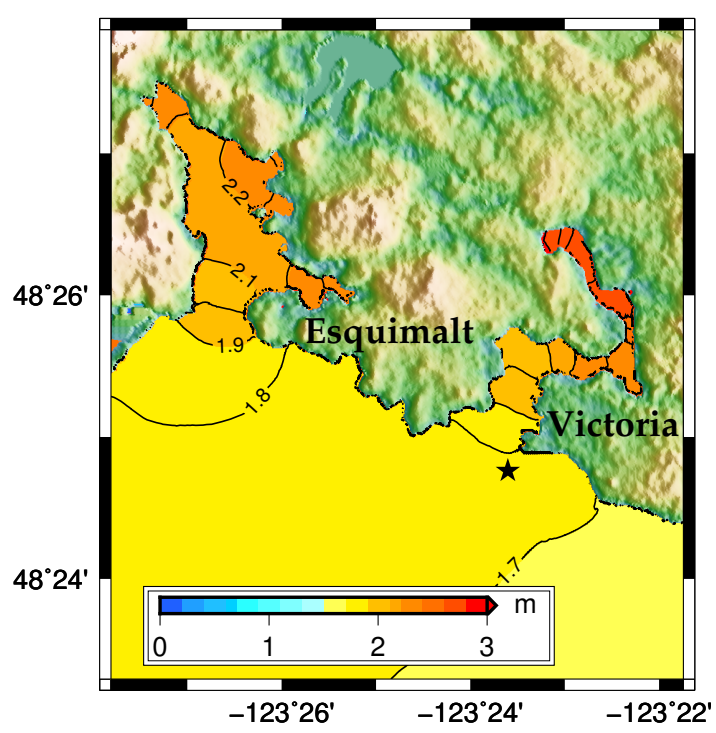

Figure 7. The contours of the maximum elevation from scenario 24 . The black star denotes the design location used to drive the experiments. 


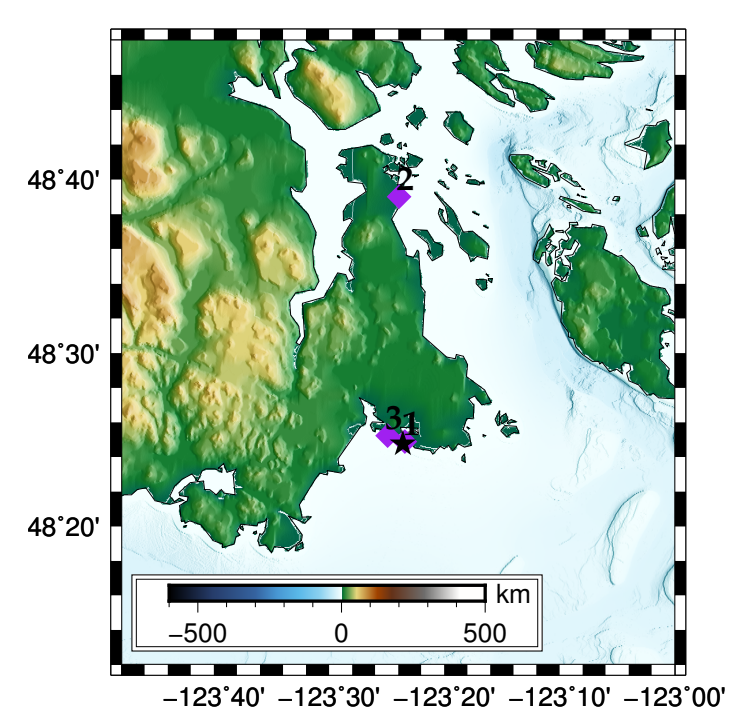

Figure 8. The location that drives the design algorithm is indicated with a black star (lon:-123.3934, lat:48.4127). The locations of two emulators (1- lon:-123.3904, lat:48.4149; 2- lon:-123.3989; lat: 48.6657; 3- lon:-123.415478, lat:48.420584) at the cell centres of the grid are displayed with purple diamonds.

resulted in maximum water surface elevation between 2.4 and $2.6 \mathrm{~m}$ in the harbor openings of Victoria and Esquimalt which increased up to $4.3 \mathrm{~m}$ due to resonance in shallow, narrow regions; the computed minimum water levels varied between -1 and $-2 \mathrm{~m}$ (AECOM, 2013). Figure 7 shows the contours of the maximum elevation of the event, as computed around the area of Victoria and Esquimalt. In the geographical opening of the harbors the maximum tsunami elevation recorded for scenario 24 ranges between 1.8-2 m. However, these values tend to increase inside the harbors which is especially evident in narrow bays and coves. Similar outputs are also observed in the predictions and are discussed in more detail in Section 4.2.

\section{Probabilistic Tsunami Hazard}

To generate the probabilistic outputs the emulators must be built and used. Hence, this stage can be split in two main parts: a) the fitting of the MOGP emulators and b) their utilisation for tsunami hazard predictions at the cell-centres of the grid (see also red panel in Figure 2).

\subsection{Fitting}

The fitting process involves the construction of the emulators using the training data with certain choices on the statistical model. The training data are the input deformation parameters and the numerical outputs of the VOLNA-OP2, represented as the maximum tsunami heights at the cell-centres of the grid at the coastline, from the 60 numerical scenarios selected by MICE. These are used in conjunction with the statistical choices for the mean and the covariance function. A zero mean function was used for each emulator. The emulators were built employing a squared exponential covariance function with the hyperparame- 
https://doi.org/10.5194/nhess-2021-63

Preprint. Discussion started: 9 March 2021

(C) Author(s) 2021. CC BY 4.0 License.

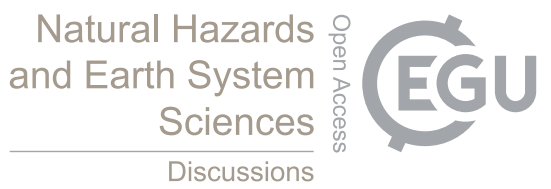

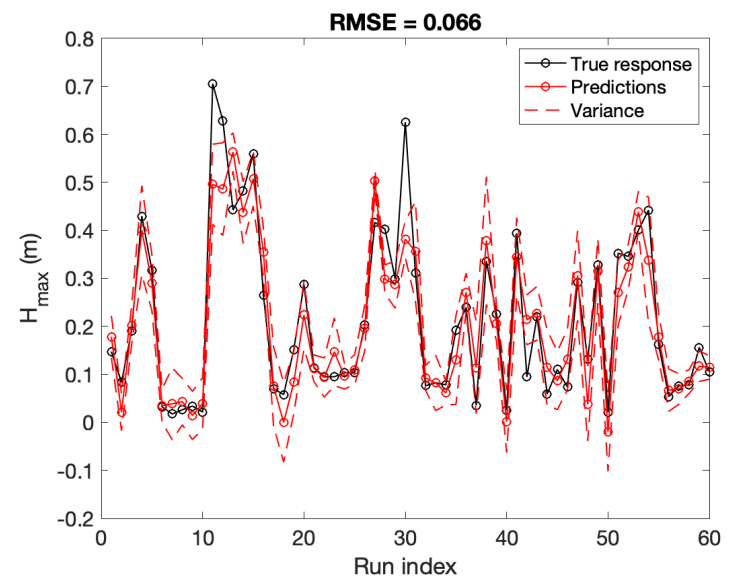

(a) location 01

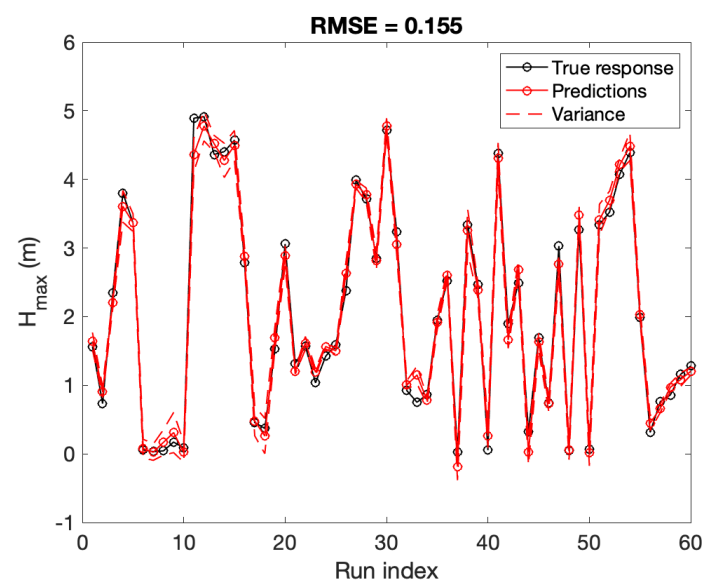

(c) location 03

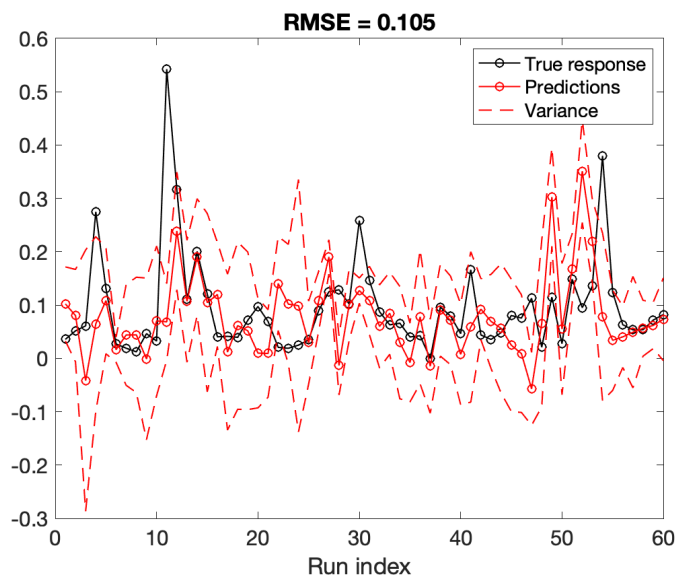

(b) location 02

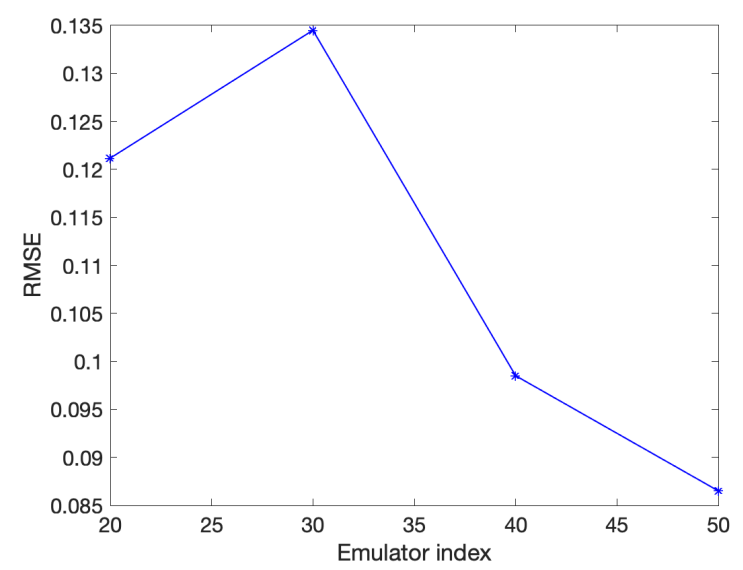

(d)

Figure 9. a-c) LOO diagnostics for points close (01), far (02) from the design location and large fluctuations in the results (03) (locations 01, $02 \& 03$ in Figure 8). The RMSE yields values that vary from 0.066 to 0.105 for locations 01 and 02 and 0.145 in location 03 . d) Error estimation for the predictions of the last 10 runs at location 001. 
ter values estimated from the training data by a Maximum Likelihood Estimation, thus no prior distributions were considered on the hyperparameter values.

The design and the built emulators were validated using the Leave-One-Out (LOO) diagnostics. Following this approach, we build an emulator by excluding each time one simulation from the training inputs and outputs; we then predict the expected outputs for the selected scenario. We test the results at three locations: one close to the gauge that was utilised in the design (locations 1, 2 and 3 in Figure 8). The plots in Figure 9a, b \& c represent the comparison between the numerical response from VOLNA-OP2 (characterised as the "true" response in the graphs) and the predicted response with the variance in these locations. As the plots demonstrate, in some cases the emulator underpredicts the response but there is an overall good agreement between the predictions and the response as the majority of the points is captured by the variance around the predictions (Fig. $9 \mathrm{a}, \mathrm{b} \& \mathrm{c})$.

The Root Mean Square Error (RMSE) is also relatively small ranging from 0.066 at location 01 to 0.145 at location 03 where the wave elevation is higher (Fig. 9a, b \& c). To gain a more comprehensive understanding of the RMSE trend and the efficacy of the design, we fit 4 emulators in location 01 using as training data the first 20, 30, 40 and 50 runs out of the 60 runs, predicting each time for the last 10 runs and calculating the RMSE (Fig. 9d). It is noticed that the error reduces to a significant extent when adding more runs to train the emulators and becomes very small for an emulator trained at 50 runs, following this trend, a smaller error would be also expected for the emulators trained at 60 runs (Fig. 9d).

\subsection{Predictions with two families of scenarios}

Once the emulators are built, the maximum tsunami elevation can be predicted for any input deformation scenario. The prediction involves the utilisation of the built emulator with a given set of inputs to calculate the mean predictions and their uncertainty on the outputs. Uncertainties are fully propagated to display sometimes complex distributions of outputs such as skewed distributions (as it in the case below): variance would not be enough to describe such uncertainties. Emulation provides a complete description of uncertainties compared to a mean and variance in more basic approaches. These inputs can be represented by the distributions of the input parameters (Fig. 10). The distributions are flexible and can be used to represent different hypothetical cases. A beta distribution is employed for each parameter, from which 2,000 scenarios are randomly selected. The shape parameters of the distributions can be utilised to express the scientific knowledge on the source. To predict the maximum tsunami heights we initially explore the likelihood of maximum uplift to vary around $4 \mathrm{~m}$, similar to the values inferred by Satake (2003) for the 1700 event, and within a range of 1-7 m (Fig. 10: $h_{\max }$, H1). A maximum subsidence is considered with the minimum values to be more likely at $1 / 2$ of the uplift (Fig. 10: $h_{\min } / h_{\max }, \mathrm{H} 1$ ). The total time of the event is considered to most likely vary around $300 \mathrm{~s}$ (Fig. 10: Total time, H1). For the most uncertain parameters we use a symmetric distribution. In more detail, the $\mathrm{a} \& \mathrm{~b}$ shape parameters of the Beta distributions used to produce the 2,000 seabed displacement scenarios in Figures 11 and 12a \& 12b have values of: Total Time: [2.5, 2], $D h_{\max } / D h_{\min }:[2,2], D d / D h_{\min }:[2,2], h_{\min } / h_{\max }:[2,2.5]$, $h_{\max }:[3,2]$ and $h_{t} / h_{\max }:[2,2]$ (Fig. 10: H1).

The MOGP emulation framework allows us to produce the probabilistic predictions of tsunami hazard in parallel for each emulator. The mean predictions are represented in the form of the histograms of the predictions at each location as shown in 

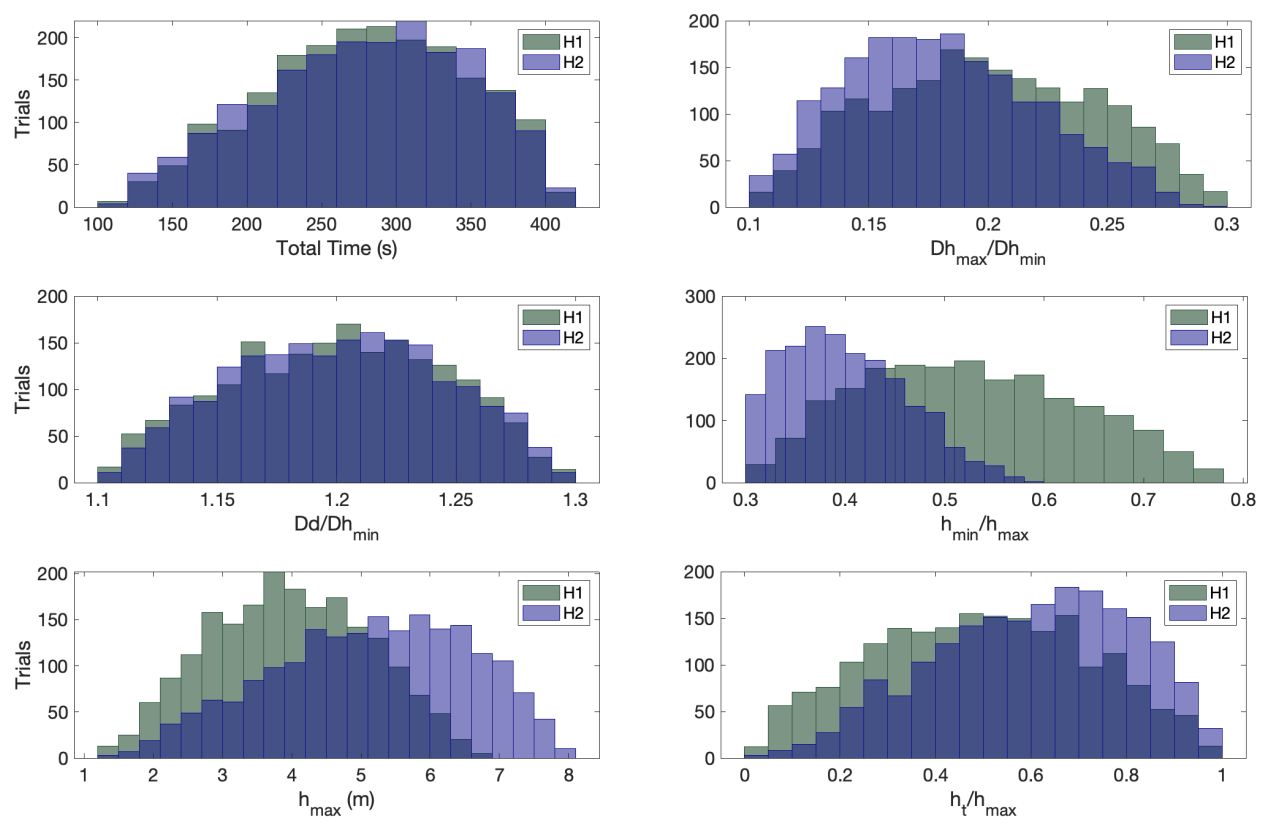

Figure 10. Input parameter distributions for two sets of hypothetical cases. Histograms of buried ruptures (H1) are depicted with dark green colour and of splay-faulting (H2) with dark blue colour.

Figure 11 for locations $1,2 \& 3$ of Figure 8 . Locations 01 and 02 display very small elevation values above the ground level due to the tsunami. It appears that the splay-faulting sensitivity is larger at locations 1 and 3 than at location 2 since the histogram of outputs shifts more towards higher values. Location 03 gives values that most likely range around $1.5 \mathrm{~m}$ depending on the selected deformation scenarios. The minimum values shown in the histograms can become negative since a positive prediction is not imposed by the emulator, but this is very rare and it does not manifest in the production of the hazard maps.

The probabilistic hazard maps in the South-East part of Vancouver island are produced based on the 50th and 90th percentiles of the emulator's predictions for the 2,000 tsunami scenarios. 5,148 coastline locations that correspond to the cell-centres of the computational grid are studied (Fig. 12a \& b). The 50th percentile of the predictions demonstrates that $67.19 \%$ of the predictions (3,459 locations) have maximum tsunami heights between 0 and $0.25 \mathrm{~m}$, whereas $86.36 \%$ (4,446 locations) falls under maximum tsunami heights of $1 \mathrm{~m}$ (Fig. 12a). When considering the 90th percentile, however the maximum tsunami height values increase. The results show that $48.77 \%$ of the predictions (2,511 locations) have maximum tsunami heights between 0 and $0.25 \mathrm{~m}, 74.86 \%(3,854)$ of the predictions falls under $1 \mathrm{~m}$ (Fig. 12b). It is observed that the maximum tsunami heights range between $1-3 \mathrm{~m}$ at $22.76 \%$ of the locations (1172 locations) (Fig. 12b).

It is noted that the fitting of each emulator takes approximately 1.5-3.0 s, whereas each emulator prediction takes ca. 0.001 


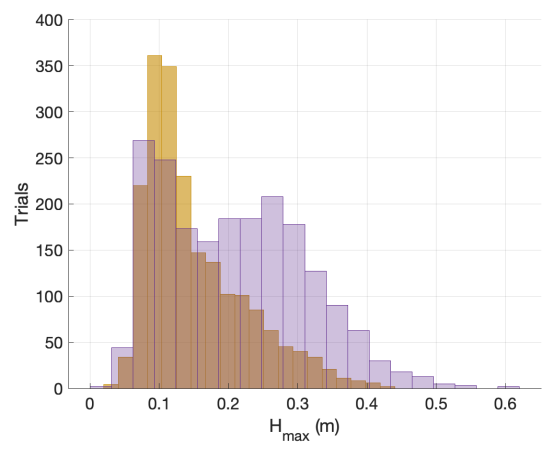

(a) location 01

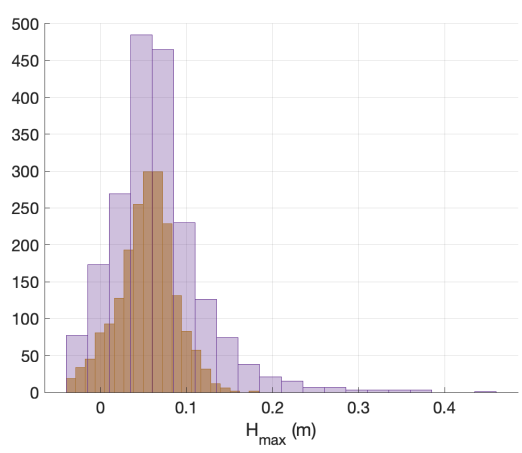

(b) location 02

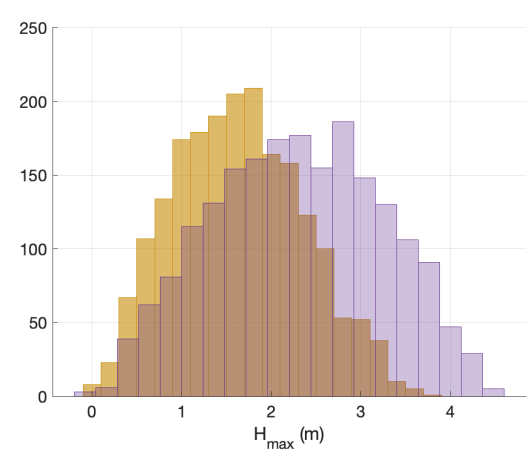

(c) location 03

Figure 11. Probabilistic predictions for three cell-centres of the grid (see locations $01,02 \& 03$ respectively in Fig. 8) for scenarios resulting from the distributions $\mathrm{H} 1$ (buried ruptures, prediction histograms in yellow) \& H2 (splay-faulting, prediction histograms in purple).

s on the KNL nodes of the Cambridge High Performance Computer Service (Peta4-KNL of the CSD3 cluster). Hence, once the emulators are built, they can be used to explore alternative rupture scenarios in fast times. Such is the hypothetical case of increased uplift in the northern part of the subduction zone caused by splay-faulting. There is a large uncertainty surrounding the presence of splay-faulting in the Northern part of the zone (Gao et al., 2018). Witter et al. (2013) have estimated the probability of splay-faulting during a megathrust earthquake to be at ca. $60 \%$. Although such enhanced vertical displacements are not likely to occur in the southern part of the zone, the tsunami impact from a short-north segment or a long rupture could be similar for British Columbia (Cherniawsky et al., 2007). To fully assess splay-faulting related tsunami hazard in Southeast Vancouver island, the complexity of the fault geometry needs to be more accurately incorporated at the initial stages of the process. The impact of an enhanced uplift is, thus, explored in a simplified form for the area here. Keeping the distributions of time and $D d / D h_{\min }$ the same, 2,000 additional rupture scenarios are predicted to study the impact of a larger rupture in the region. Larger rupture scenarios may be characterised by an increased uplift and a more abrupt vertical deformation, the shapes of the parameter distributions for $D h_{\max } / D h_{\min }, h_{\max }$ and $h_{t} / h_{\max }$ can be, thus, defined by $a=[2,3,3]$ and $b=[3,2,2]$ respectively (Fig. 10: H2). These values raise the likelihood of the maximum uplift to vary between 5-7 m (Fig. 10: H2). The ratio of $h_{\min } / h_{\max }$ is estimated to be lower ( $a=1.5, b=3$ ), as the maximum subsidence in worst-case rupture scenarios is expected to be at ca. $-2 \mathrm{~m}$ (AECOM, 2013; Witter et al., 2013).

Looking at the 50th percentile of the predictions for $\mathrm{H} 2$, it is shown that the maximum wave heights from these scenarios are increased (Fig.12c). In Figure 12c, 57.98\% (2.985 locations) of the predicted maximum tsunami heights falls between 0.0-0.25 $\mathrm{m}$, whereas $79.51 \%$ (4,093 locations) falls under $1 \mathrm{~m}$. In both hypothetical cases the large majority of the predicted maximum wave heights falls under $2 \mathrm{~m}$ (98.17\% of the locations in Figure 12a and 94.09\% in Figure 12c). However, when considering the 90th percentile of the predictions, the outputs become more severe (Fig. 12d). In this case, only slightly more than the one third of the maximum tsunami wave heights ( $35.18 \%$ of the locations) falls within the range of $0-0.25 \mathrm{~m}$. The maximum wave heights are below $1 \mathrm{~m}$ at $63.81 \%(3,285)$ of the locations, and range between $1-3 \mathrm{~m}$ at $27.93 \%(1,438)$ of the locations. 


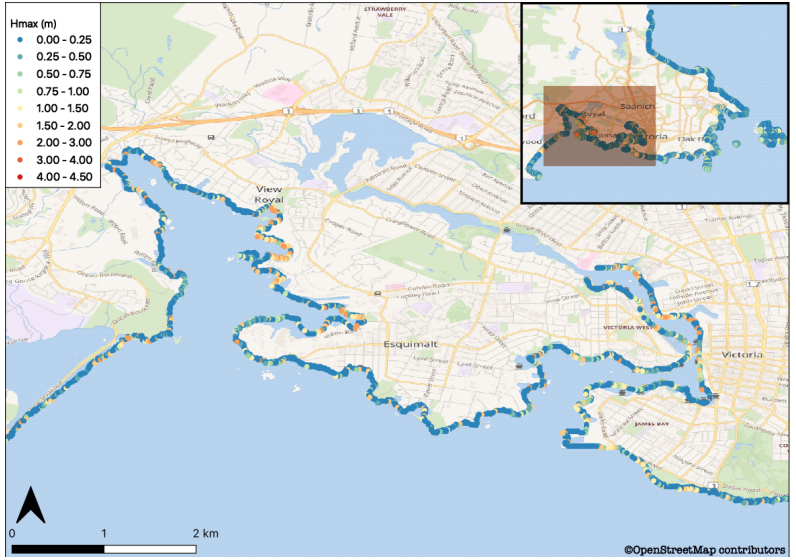

(a) 50th percentile: $\mathrm{H} 1$

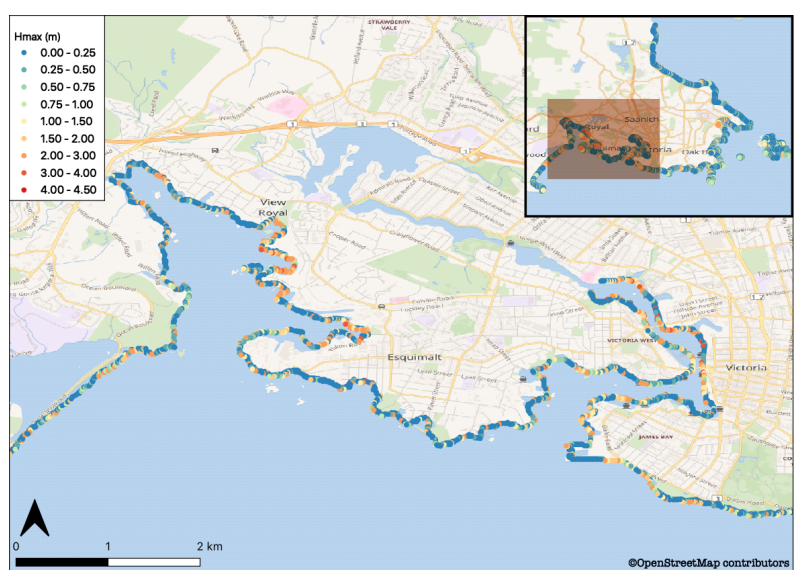

(c) 50th percentile: $\mathrm{H} 2$

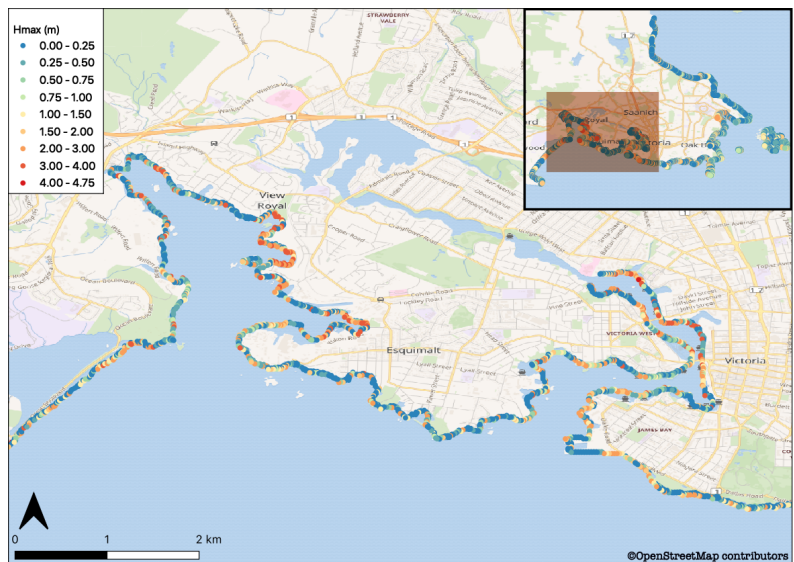

(b) 90th percentile: $\mathrm{H} 1$

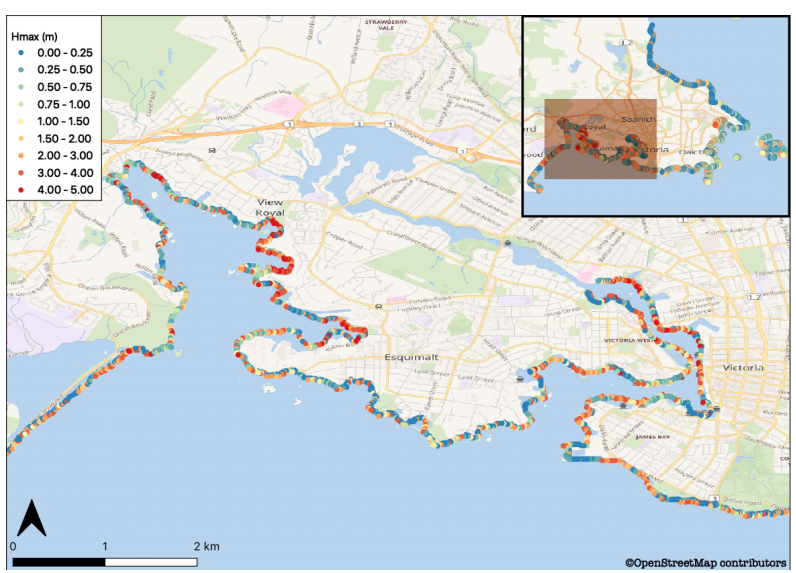

(d) 90th percentile: $\mathrm{H} 2$

Figure 12. The percentiles (50th left, 90th right) of the mean predictions at the cell centres of the computational grid, for buried ruptures (H1) and for splay-faulting (H2). The circles show the locations of the emulators. The figures were produced with the QGIS software using as base-maps the Wikimedia layers with data provided by OpenStreetMap contributors, 2021. Distributed under a Creative Commons BY-SA License. 
Maximum tsunami wave heights between 3-4 $\mathrm{m}$ are recorded at $6.29 \%$ of the locations (Fig. 12d) as opposed to $2.33 \%$ in the previous case (Fig. 12b). Following similar procedures, expert knowledge on the rupture characteristics can be translated to probabilistic tsunami hazard outputs.

Tsunami amplification is especially apparent at narrow bays and coves inside the Victoria and Esquimalt harbors and is likely the outcome of wave resonance (Fig. 12). Wave amplification in harbors and small bays has also been observed in other numerical studies in the area (Cherniawsky et al., 2007; AECOM, 2013; Fine et al., 2018). In their numerical studies of large earthquake-induced tsunamis, Cherniawsky et al. (2007) found maximum elevations above $4 \mathrm{~m}$ at the Northwest shallow parts of Esquimalt harbour with the second wave peak being larger than the first one in some locations. Similar values (ca. $4.3 \mathrm{~m}$ ) have been computed by AECOM (2013) in the area. These higher values are possibly the effect of wave resonance attributed to the regional geomorphology. Wave resonance has been observed in Port Alberni, located at the head of a narrow inlet in the west past of Vancouver island, during the 1964 Alaskan earthquake (Fine et al., 2008). The recorded wave heights in the port were 3-4 times larger than in the adjacent areas, often recorded in the third or later waves, and the tsunami oscillations continued for days after the event (Fine et al., 2008). It is likely that local topographic features can contribute to tsunami amplification also in other parts of the region.

\section{Conclusions}

In this work, a sequential design algorithm was employed for the conduction of the computational experiments for earthquake generated tsunami hazard in the Cascadia subduction zone. This approach aided an informative, innovative selection of the sets of numerical experiments in order to train the statistical emulators. It forms the first of its kind, to the authors' knowledge, which involves the application of a sequential design algorithm for real-case tsunami hazard prediction through emulation. Focusing the high-resolution computations in the Southeast Vancouver island, the maximum tsunami wave heights were predicted at 5,148 coastal locations with the utilisation of the emulators. Once the emulators are built, expert knowledge can be facilitated to swiftly assess hazard in the region. The flexibility of the method allowed, here, to predict thousands of scenarios in a few moments of time under different parameter set-ups. The probabilistic outputs demonstrated in the study resulted from 2,000 potential rupture scenarios, the parameters of which were distributed following two hypothetical cases $(2,000$ predictions/case). The emulators allowed us to produce probabilistic hazard maps that assess the tsunami potential in the area (Fig. 11). This forms one way of representing the mean predictions under a probabilistic framework. Alternatively one could present other probabilistic statements, for instance assessing the probability of exceeding some given threshold of maximum tsunami run-up. This would particularly to plan preventive measures such as built structures or natural hazard solutions.

The predictions showed a high dependence of the maximum wave heights on the maximum uplift during the rupture. In the areas of Victoria and Esquimalt, the majority of the maximum predicted wave heights tend to be under $1 \mathrm{~m}$ and most likely under $0.25 \mathrm{~m}$. However, wave amplification is observed inside the harbors and especially in narrow bays and coves, possibly as an effect of wave resonance. When considering the maximum uplift distributions with a higher likelihood ranging between 
https://doi.org/10.5194/nhess-2021-63

Preprint. Discussion started: 9 March 2021

(c) Author(s) 2021. CC BY 4.0 License.

4-7 $\mathrm{m}$, the 90th percentile of the predictions shows that maximum wave heights range between 3-4 $\mathrm{m}$ at $6.29 \%$ of the locations studied. In rare cases (at 1.9\% of the locations) maximum wave heights may exceed the threshold of $4 \mathrm{~m}$, falling within a range of 4-4.9 $\mathrm{m}$. These values have to be further assessed to produce a probabilistic risk assessment for the area.

This study expands on the methodology and the development of the workflow to build the emulators under a sequential design approach. As so, there are some aspects that need to be considered in future work to further refine the probabilistic outputs.

340 These span from the tsunami generation to the inundation. In this case, an idealised geometry was used for the source, and the current results agree with the numerical studies of more incorporating fault geometries. However to fully explore the complexity of the rupture, future work would benefit from the integration of compound rupture characteristics, especially when it comes to splay-faulting consideration. Furthermore, gaps and mismatches in the digital elevation data should be accounted for and incorporated in the modelling for a more finely resolved representation. Finally, to produce a complete hazard assessment in the region, probabilistic tsunami inundation should be studied and integrated in the results.

Code availability. MOGP-MICE: https://github.com/alan-turing-institute/mogp_emulator, VOLNA-OP2: https://github.com/reguly/volna.git, https://github.com/DanGiles/volna.git

\section{Appendix A}

Table A1: Deformation scenarios selected by MICE to be used as source in the tsunami simulations.

\begin{tabular}{lllllll}
\hline Scenario & Time $(\mathrm{s})$ & $D h_{\max } / D h_{\min }$ & $D d / D h_{\min }$ & $h_{\min } / h_{\max }$ & $h_{\max }(\mathrm{m})$ & $h_{t} / h_{\max }$ \\
\hline 01 & 415 & 0.18876 & 1.14439 & 0.65090 & 3.57400 & 0.89827 \\
02 & 118 & 0.11066 & 1.18921 & 0.52726 & 2.25844 & 0.51710 \\
03 & 322 & 0.26905 & 1.29754 & 0.40622 & 5.15068 & 0.24049 \\
04 & 269 & 0.15534 & 1.24382 & 0.79471 & 6.92122 & 0.05661 \\
05 & 168 & 0.25932 & 1.10375 & 0.36200 & 6.27256 & 0.73954 \\
06 & 324 & 0.19257 & 1.13175 & 0.58639 & 1.20224 & 0.78907 \\
07 & 333 & 0.29182 & 1.29837 & 0.46602 & 1.14988 & 0.36028 \\
08 & 321 & 0.20928 & 1.11077 & 0.78350 & 1.07064 & 0.68148 \\
09 & 415 & 0.28950 & 1.14091 & 0.31510 & 1.24523 & 0.87016 \\
10 & 396 & 0.28166 & 1.26802 & 0.42280 & 1.32406 & 0.98242 \\
11 & 203 & 0.28396 & 1.10121 & 0.40705 & 7.95143 & 0.95837 \\
12 & 142 & 0.13749 & 1.11697 & 0.54020 & 7.95486 & 0.98510 \\
13 & 346 & 0.17685 & 1.12009 & 0.47852 & 7.80322 & 0.84656
\end{tabular}


https://doi.org/10.5194/nhess-2021-63

Preprint. Discussion started: 9 March 2021

(c) Author(s) 2021. CC BY 4.0 License.
Natural Hazards and Earth System Sciences

Discussions

\begin{tabular}{|c|c|c|c|c|c|c|}
\hline 14 & 173 & 0.13373 & 1.23984 & 0.34994 & 7.98143 & 0.69699 \\
\hline 15 & 336 & 0.23286 & 1.27498 & 0.55781 & 7.91868 & 0.67009 \\
\hline 16 & 237 & 0.13273 & 1.27853 & 0.54955 & 5.63092 & 0.98188 \\
\hline 17 & 343 & 0.12069 & 1.13049 & 0.53715 & 2.21708 & 0.01722 \\
\hline 18 & 412 & 0.10322 & 1.29979 & 0.36434 & 2.54273 & 0.07739 \\
\hline 19 & 120 & 0.29840 & 1.18448 & 0.73063 & 3.40402 & 0.22795 \\
\hline 20 & 199 & 0.12152 & 1.10658 & 0.76242 & 5.12636 & 0.97087 \\
\hline 21 & 250 & 0.20656 & 1.12431 & 0.38110 & 3.47216 & 0.41432 \\
\hline 22 & 106 & 0.15650 & 1.19044 & 0.37480 & 3.91755 & 0.76439 \\
\hline 23 & 227 & 0.19896 & 1.18189 & 0.39482 & 3.34181 & 0.06342 \\
\hline 24 & 281 & 0.18439 & 1.18176 & 0.31049 & 4.09125 & 0.36047 \\
\hline 25 & 132 & 0.22202 & 1.17230 & 0.32744 & 4.04066 & 0.50855 \\
\hline 26 & 403 & 0.10581 & 1.15201 & 0.32755 & 5.95859 & 0.61608 \\
\hline 27 & 121 & 0.25499 & 1.22249 & 0.74695 & 6.03230 & 0.95641 \\
\hline 28 & 109 & 0.22550 & 1.29511 & 0.76429 & 5.62019 & 0.93289 \\
\hline 29 & 398 & 0.11921 & 1.25359 & 0.45199 & 6.48259 & 0.53838 \\
\hline 30 & 137 & 0.26685 & 1.20942 & 0.77697 & 6.98940 & 0.85119 \\
\hline 31 & 148 & 0.27108 & 1.12253 & 0.56776 & 6.50266 & 0.01205 \\
\hline 32 & 163 & 0.27646 & 1.14596 & 0.78362 & 2.18301 & 0.97280 \\
\hline 33 & 159 & 0.27577 & 1.11221 & 0.32033 & 2.62842 & 0.86107 \\
\hline 34 & 224 & 0.28072 & 1.23412 & 0.77180 & 2.09684 & 0.98993 \\
\hline 35 & 213 & 0.10919 & 1.19239 & 0.64663 & 4.66165 & 0.09996 \\
\hline 36 & 361 & 0.19797 & 1.10408 & 0.62892 & 5.58353 & 0.34304 \\
\hline 37 & 128 & 0.18069 & 1.28457 & 0.30279 & 1.01087 & 0.08392 \\
\hline 38 & 394 & 0.15899 & 1.11494 & 0.44509 & 7.50061 & 0.01201 \\
\hline 39 & 413 & 0.27468 & 1.15351 & 0.57142 & 5.35065 & 0.23606 \\
\hline 40 & 119 & 0.14168 & 1.19017 & 0.36867 & 1.09176 & 0.34923 \\
\hline 41 & 410 & 0.20819 & 1.11398 & 0.70190 & 7.89979 & 0.56523 \\
\hline 42 & 132 & 0.10632 & 1.20853 & 0.78520 & 3.21606 & 0.59659 \\
\hline 43 & 130 & 0.29382 & 1.10213 & 0.50885 & 4.80543 & 0.69270 \\
\hline 44 & 139 & 0.28712 & 1.10695 & 0.62522 & 1.68192 & 0.43708 \\
\hline 45 & 361 & 0.25899 & 1.29084 & 0.45390 & 3.75642 & 0.93926 \\
\hline 46 & 202 & 0.16599 & 1.24416 & 0.76199 & 2.22083 & 0.02408 \\
\hline 47 & 141 & 0.10912 & 1.27527 & 0.36927 & 6.49197 & 0.02806 \\
\hline 48 & 234 & 0.26551 & 1.29713 & 0.73814 & 1.38065 & 0.03826 \\
\hline
\end{tabular}


https://doi.org/10.5194/nhess-2021-63

Preprint. Discussion started: 9 March 2021

(c) Author(s) 2021. CC BY 4.0 License.

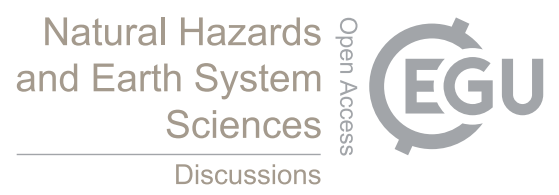

Discussions

$\begin{array}{llll}1.29673 & 0.55071 & 6.42067 & 0.26797 \\ 1.29293 & 0.63737 & 1.18291 & 0.61683 \\ 1.20031 & 0.79548 & 6.01218 & 0.97036 \\ 1.21302 & 0.45755 & 6.80059 & 0.32854 \\ 1.21763 & 0.48670 & 7.53270 & 0.41969 \\ 1.14711 & 0.71566 & 7.81272 & 0.03208 \\ 1.27150 & 0.66456 & 4.61712 & 0.26980 \\ 1.27388 & 0.30216 & 2.26079 & 0.90427 \\ 1.20553 & 0.34914 & 2.87207 & 0.80172 \\ 1.26487 & 0.55128 & 2.49722 & 0.52515 \\ 1.12818 & 0.76070 & 2.63381 & 0.65489 \\ 1.24347 & 0.68209 & 2.90920 & 0.56893\end{array}$

Author contributions. DS carried out the analysis and writing. JB and SG contributed to the analysis and writing. SG also supervised the analysis.

Competing interests. The authors declare that they have no conflict of interest.

Acknowledgements. We gratefully acknowledge the support, advice and fruitful discussions with Dr Simon Day. His help was important in the first stages of the study for the conceptualisation of the seabed deformation and the parameterisation. We are also thankful to Dr Devaraj Gopinathan, for his support with the meshing techniques for the numerical simulations. SG was supported by the Alan Turing Institute project "Uncertainty Quantification of complex computer models. Applications to tsunami and climate" under the EPSRC grant EP/N510129/1. Finally, we would like to thank the Research Software Engineering team at the Alan Turing Institute, and especially Dr Eric Daub and Dr Oliver Strickson for their help with MOGP and the automation of the workflows. 


\section{References}

AECOM: Modeling of potential tsunami inundation limits and run-up. Report for the capital region district, p. $60242933,2013$.

Atwater, B. and Hemphill-Haley, E.: Recurrence Intervals for Great Earthquakes of the Past 3,500 Years at Northeastern Willapa Bay, Washington, USGS professional paper, 1576, 1997.

Beck, J. and Guillas, S.: Sequential Design with Mutual Information for Computer Experiments (MICE): Emulation of a Tsunami Model, SIAM/ASA Journal on Uncertainty Quantification, 4, 739-766, https://doi.org/10.1137/140989613, 2016.

Behrens, J. and Dias, F.: New computational methods in tsunami science, Philosophical Transactions of the Royal Society A: Mathematical, Physical and Engineering Sciences, 373, 20140 382, https://doi.org/10.1098/rsta.2014.0382, 2015.

Bilek, S. L. and Lay, T.: Subduction zone megathrust earthquakes, Geosphere, 14, 1468-1500, https://doi.org/10.1130/GES01608.1, 2018.

Cherniawsky, J. Y., Titov, V. V., Wang, K., and Li, J.-Y.: Numerical Simulations of Tsunami Waves and Currents for Southern Vancouver Island from a Cascadia Megathrust Earthquake, Pure and Applied Geophysics, 164, 465-492, https://doi.org/10.1007/s00024-006-0169-0, 2007.

Clague, J., Munro, A., and Murty, T.: Tsunami Hazard and Risk in Canada, Natural Hazards, 28, 435-463, https://doi.org/10.1023/A:1022994411319, 2003.

Clague, J. J., Bobrowsky, P. T., and Hutchinson, I.: A review of geological records of large tsunamis at Vancouver Island, British Columbia, and implications for hazard, Quaternary Science Reviews, 19, 849-863, https://doi.org/10.1016/S0277-3791(99)00101-8, 2000.

Denamiel, C., Šepić, J., Huan, X., Bolzer, C., and Vilibić, I.: Stochastic Surrogate Model for Meteotsunami Early Warning System in the Eastern Adriatic Sea, Journal of Geophysical Research: Oceans, 124, 8485-8499, https://doi.org/10.1029/2019JC015574, 2019.

Fine, I., Cherniawsky, J., Rabinovich, A., and Stephenson, F.: Numerical Modeling and Observations of Tsunami Waves in Alberni Inlet and Barkley Sound, British Columbia, Pure and Applied Geophysics, 165, 2019-2044, https://doi.org/10.1007/s00024-008-0414-9, 2008.

Fine, I. V., Thomson, R. E., Lupton, L. M., and Mundschutz, S.: Numerical Modelling of a Cascadia Subduction Zone Tsunami at the Canadian Coast Guard Base in Victoria, British Columbia, Canadian Technical Report of Hydrography and Ocean Sciences, p. $37,2018$.

Fujiwara, T., Kodaira, S., No, T., Kaiho, Y., Takahashi, N., and Kaneda, Y.: The 2011 Tohoku-Oki Earthquake: Displacement Reaching the Trench Axis, Science (New York, N.Y.), 334, 1240, https://doi.org/10.1126/science.1211554, 2011.

Gao, D., Wang, K., Insua, T. L., Sypus, M., Riedel, M., and Sun, T.: Defining megathrust tsunami source scenarios for northernmost Cascadia, Natural Hazards, 94, 445-469, https://doi.org/10.1007/s11069-018-3397-6, http://link.springer.com/10.1007/s11069-018-3397-6, 2018.

Giles, D., Kashdan, E., Salmanidou, D. M., Guillas, S., and Dias, F.: Performance analysis of Volna-OP2 - massively parallel code for tsunami modelling, Computers \& Fluids, 209, 104 649, https://doi.org/10.1016/j.compfluid.2020.104649, 2020.

Goldfinger, C., Nelson, C. H., and Johnson, J. E. a.: Holocene Earthquake Records from the Cascadia Subduction Zone and Northern San Andreas Fault Based on Precise Dating of Offshore Turbidites, Annual Review of Earth and Planetary Sciences, 31, 555-577, https://doi.org/10.1146/annurev.earth.31.100901.141246, 2003.

Goldfinger, C., Nelson, C., Morey, A., Johnson, J., Patton, J., Karabanov, E., Gutiérrez-Pastor, J., Eriksson, A., Gràcia, E., Dunhill, G., Enkin, R., Dallimore, A., and Vallier, T.: Turbidite Event History: Methods and Implications for Holocene Paleoseismicity of the Cascadia Subduction Zone. U.S. Geological Survey Professional Paper 1661-F, Turbidite Event History-Methods and Implications for Holocene Paleoseismicity of the Cascadia Subduction Zone, 2012.

Gopinathan, D., Heidarzadeh, M., and Guillas, S.: Probabilistic Quantification of Tsunami Currents in Karachi Port, Makran Subduction 
https://doi.org/10.5194/nhess-2021-63

Preprint. Discussion started: 9 March 2021

(c) Author(s) 2021. CC BY 4.0 License.

Guillas, S., Sarri, A., Day, S. J., Liu, X., and Dias, F.: Functional emulation of high resolution tsunami modelling over Cascadia, The Annals of Applied Statistics, 12, 2023-2053, https://doi.org/10.1214/18-AOAS1142, 2018.

Ishii, M., Shearer, P. M., Houston, H., and Vidale, J. E.: Extent, duration and speed of the 2004 Sumatra-Andaman earthquake imaged by the Hi-Net array, Nature, 435, 933-936, https://doi.org/10.1038/nature03675, 2005.

Krause, A., Singh, A., and Guestrin, C.: Near-Optimal Sensor Placements in Gaussian Processes: Theory, Efficient Algorithms and Empirical Studies, Journal of Machine Learning Research, 9, 235-284, https://doi.org/10.1145/1390681.1390689, 2008.

Lay, T.: A review of the rupture characteristics of the 2011 Tohoku-oki Mw 9.1 earthquake, Tectonophysics, 733, 4-36, https://doi.org/10.1016/j.tecto.2017.09.022, 2018.

Maksymowicz, A., Chadwell, C. D., Ruiz, J., Tréhu, A. M., Contreras-Reyes, E., Weinrebe, W., Díaz-Naveas, J., Gibson, J. C., Lonsdale, P., and Tryon, M. D.: Coseismic seafloor deformation in the trench region during the Mw8.8 Maule megathrust earthquake, Scientific Reports, 7, 45 918, https://doi.org/10.1038/srep45918, 2017.

McCaffrey, R.: Earthquakes and Crustal Deformation, in: Encyclopedia of Solid Earth Geophysics, edited by Gupta, H. K., pp. 218-226, Springer Netherlands, Dordrecht, https://doi.org/10.1007/978-90-481-8702-7_2, series Title: Encyclopedia of Earth Sciences Series, 2011.

Park, H., Cox, D. T., Alam, M. S., and Barbosa, A. R.: Probabilistic Seismic and Tsunami Hazard Analysis Conditioned on a Megathrust Rupture of the Cascadia Subduction Zone, Frontiers in Built Environment, 3, 32, https://doi.org/10.3389/fbuil.2017.00032, http://journal. frontiersin.org/article/10.3389/fbuil.2017.00032/full, 2017.

Priest, G. R., Goldfinger, C., Wang, K., Witter, R. C., Zhang, Y., and Baptista, A. M.: Confidence levels for tsunami-inundation limits in northern Oregon inferred from a 10,000-year history of great earthquakes at the Cascadia subduction zone, Natural Hazards, 54, 27-73, https://doi.org/10.1007/s11069-009-9453-5, http://link.springer.com/10.1007/s11069-009-9453-5, 2010.

415 Reguly, I. Z., Giles, D., Gopinathan, D., Quivy, L., Beck, J. H., Giles, M. B., Guillas, S., and Dias, F.: The VOLNA-OP2 tsunami code (version 1.5), Geoscientific Model Development, 11, 4621-4635, https://doi.org/10.5194/gmd-11-4621-2018, 2018.

Salmanidou, D. M., Guillas, S., Georgiopoulou, A., and Dias, F.: Statistical emulation of landslide-induced tsunamis at the Rockall Bank, NE Atlantic, Proceedings of the Royal Society A: Mathematical, Physical and Engineering Sciences, 473, 20170026, https://doi.org/10.1098/rspa.2017.0026, 2017.

Salmanidou, D. M., Heidarzadeh, M., and Guillas, S.: Probabilistic Landslide-Generated Tsunamis in the Indus Canyon, NW Indian Ocean, Using Statistical Emulation, Pure and Applied Geophysics, 176, 3099-3114, https://doi.org/10.1007/s00024-019-02187-3, 2019.

Sarri, A., Guillas, S., and Dias, F.: Statistical emulation of a tsunami model for sensitivity analysis and uncertainty quantification, Natural Hazards and Earth System Sciences, 12, 2003-2018, https://doi.org/10.5194/nhess-12-2003-2012, 2012.

Satake, K.: Fault slip and seismic moment of the 1700 Cascadia earthquake inferred from Japanese tsunami descriptions, Journal of Geophysical Research, 108, 2535, https://doi.org/10.1029/2003JB002521, 2003.

Satake, K., Shimazaki, K., Tsuji, Y., and Ueda, K.: Time and size of a giant earthquake in Cascadia inferred from Japanese tsunami records of January 1700, Nature, 379, 246-249, https://doi.org/10.1038/379246a0, 1996.

Snelling, B., Neethling, S., Horsburgh, K., Collins, G., and Piggott, M.: Uncertainty Quantification of Landslide Generated Waves Using Gaussian Process Emulation and Variance-Based Sensitivity Analysis, Water, 12, 416, https://doi.org/10.3390/w12020416, 2020.

430 Sraj, I., Mandli, K. T., Knio, O. M., Dawson, C. N., and Hoteit, I.: Uncertainty quantification and inference of Manning's friction coefficients using DART buoy data during the Tōhoku tsunami, Ocean Modelling, 83, 82-97, https://doi.org/10.1016/j.ocemod.2014.09.001, 2014. 
https://doi.org/10.5194/nhess-2021-63

Preprint. Discussion started: 9 March 2021

(c) Author(s) 2021. CC BY 4.0 License.

(c) (1)

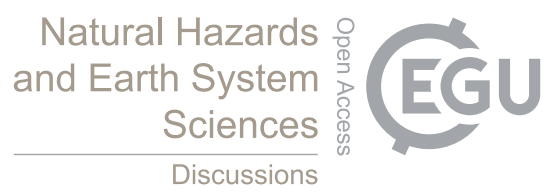

Wang, K., Wells, R., Mazzotti, S., Hyndman, R. D., and Sagiya, T.: A revised dislocation model of interseismic deformation of the Cascadia subduction zone: Revised Dislocation Model of Interseismic Deformation, Journal of Geophysical Research: Solid Earth, 108, https://doi.org/10.1029/2001JB001227, 2003.

435 Witter, R., Zhang, Y., Wang, K.-K., Priest, G., Goldfinger, C., Stimely, L., English, J., and Ferro, P.: Simulated tsunami inundation for a range of Cascadia megathrust earthquake scenarios at Bandon, Oregon, USA, Geosphere, 9, https://doi.org/10.1130/GES00899, 2013. 